\title{
Historical overview of development in methods to estimate burden of disease due to congenital disorders
}

\author{
Bernadette Modell $^{1} \cdot$ Matthew W Darlison ${ }^{1}$ (D) - Joy E Lawn ${ }^{2}$
}

Received: 6 March 2018 / Accepted: 23 August 2018 / Published online: 12 September 2018

(C) The Author(s) 2018

\begin{abstract}
Congenital disorders (often also called birth defects) are an important cause of mortality and disability. They encompass a wide range of disorders with differing severity that can affect any aspect of structure or function. Understanding their epidemiology is important in developing appropriate services both for their prevention and treatment. The need for epidemiological data on congenital disorders has been recognised for many decades. Here, we provide a historical overview of work that has led to the development of the Modell Global Database of Congenital Disorders (MGDb) - a tool that can be used to generate evidencebased country, regional and global estimates of the birth prevalence and outcomes of congenital disorders.
\end{abstract}

Keywords Congenital disorders $\cdot$ Congenital anomalies $\cdot$ Genetic disorders $\cdot$ Rare diseases epidemiology $\cdot$ Mortality $\cdot$ Disability

\section{Historical background}

Congenital disorders (often also called birth defects) are an important cause of mortality and disability. They encompass a wide range of disorders with differing severity that can affect any aspect of structure or function. The need for epidemiological data on congenital disorders was recognised in the aftermath of the Second World War, when the United Nations Scientific Committee on the Effects of Atomic Radiation (UNSCEAR) was established "to collect and evaluate information on the levels and effects of exposure to ionizing radiation" (United Nations Scientific Committee on the Effects of Atomic Radiation 1977; United Nations Scientific Committee on the Effects of Atomic Radiation 1982; United Nations Scientific Committee on the Effects of Atomic Radiation 1986). Accordingly, meticulous controlled studies on the prevalence of congenital disorders in the populations of Hiroshima and Nagasaki were conducted on the assumption

This is part of the SI on Methods in Community Genetics

Matthew W Darlison

m.darlison@ucl.ac.uk

1 WHO Collaborating Centre for Community Genetics, Centre for Health Informatics and Multiprofessional Education (CHIME), University College London, London, UK

2 London School of Hygiene \& Tropical Medicine, London, UK that an increased mutation rate would manifest as an increased birth prevalence of affected children (Schull 1958; Schull 2003; Schull et al. 1981).

At the same time, a combination of increasing technical diagnostic ability, the observed effects of rubella infection, and the thalidomide disaster of the 1960s led to increased recognition of the contribution of congenital disorders to early death and disability, the potential power of interventions and the need for ongoing surveillance. Accordingly, the World Health Organization encouraged epidemiological studies, the development of congenital anomaly registries and the construction of databases for common genetically determined disorders. The importance of surveillance was further reinforced by the thalidomide disaster in the 1960s.

\section{Congenital anomaly registries}

Congenital anomaly registries were progressively established from the 1950s onwards. Two of the earliest registries have made unique contributions to global epidemiology. The first is the British Columbia Health Surveillance Registry, which was initiated in 1952 (Baird 1987). Whilst most congenital anomaly registries include only severe disorders associated with structural change, i.e. the "congenital malformations, deformations and chromosomal disorders" included in chapter XV11 of ICD10 (World Health Organization 1992), this registry also included single-gene disorders. The reported birth prevalences of rare single-gene disorders from this registry are 
relevant today, and provide the input data used in the Modell Global Database of Congenital Disorders (MGDb) (Blencowe et al. 2018; Modell et al. 2016). The second, the national Hungarian Congenital Abnormality Registry, initiated in 1962 (Czeizel 1997) was exceptional because it was partnered with a public health initiative, the Hungarian Optimal Planning Programme (Czeizel 2012; Czeizel et al. 1998). This combination enabled many invaluable studies, including a pioneering assessment of the burden of congenital anomalies in terms of years of life lost, lived with disability or lived effectively cured (Czeizel and Sankaranarayanan 1984), estimates of the power of interventions for prevention and care (Czeizel et al. 1993), and randomised controlled trials of interventions aiming to improve birth outcomes, including preconceptional supplementation with multivitamins (Czeizel and Dudas 1992) or folic acid (Czeizel et al. 1996).

Particularly important from the point of view of global epidemiology, two "umbrella registries" were initiated in 1974 to collect, standardise and harmonise birth prevalence data from individual registries and regularly publish key reference data (Moorthie et al. 2017b). The European Surveillance of Congenital Anomalies and Twins network (EUROCAT, www.eurocat-network.eu) aims to record the majority of severe congenital anomalies. The International Clearing House for Birth Defect Surveillance and Research (ICBDSR, www.icbdsr.org) collects data from countries at all levels of development, and so reports on the approximately $30 \%$ of congenital anomalies that can be reliably diagnosed around the time of birth in the absence of advanced facilities. These umbrella registries have the outstanding advantage that (when possible) they report all birth outcomes (termination of pregnancy for fetal impairment, fetal death/stillbirth, live birth), and so enable quantification of the effect of interventions that affect birth prevalence or birth outcomes.

\section{Databases of genetically determined disorders}

Key additional resources are three databases on genetic determinants of disorders whose birth prevalence differs between populations-ABO and rhesus blood groups (Mourant et al. 1976), haemoglobin disorders and G6PD deficiency (Livingstone 1985) and prevalence of parental consanguinity (Bittles and Black 2015).

\section{Classical epidemiological studies}

Table 1 shows classical epidemiological studies that have examined the birth prevalence of congenital disorders. These studies also have the advantage that they predate the introduction of interventions that reduce affected birth prevalence (e.g. periconceptional vitamin supplementation, termination of pregnancy for fetal impairment), or increase detection rates (e.g. routine fetal anomaly scanning, sophisticated neonatal screening). Although the range of diagnoses included differed between studies, and most studies were conducted in populations of European origin, the rates observed were broadly consistent, and were generally considered to apply worldwide (Baird et al. 1988).

AC Stevenson was the first to attempt to measure "the load of hereditary defects in human populations", based on the number and age distribution of patients referred to his Northern Ireland clinic (Stevenson 1959). This study includes valuable estimates of birth prevalence and early mortality at a time when only supportive care was available. It led the WHO to conduct a comparative study of the birth prevalence of selected congenital anomalies in 24 centres representing all WHO regions, to review the global prevalence and management of haemoglobin disorders and to publish three technical reports (Stevenson et al. 1966; World Health Organization 1966; World Health Organization 1972).

\section{Towards development of a global epidemiological picture}

In the early 1980s, Anver Kuliev, then director of the WHO Hereditary Diseases Programme, reviewed the available data and identified the three key elements of Community Genetics - epidemiology, audit of the effect of interventions (surveillance) and information and education (World Health Organization 1985). Accordingly, he initiated development of a global epidemiological picture, starting with country-specific estimates for the haemoglobin disorders (Modell and Darlison 2008). The work was continued with support from the Wellcome Trust and the WHO Office for the Eastern Mediterranean Region (Alwan et al. 1997; Christianson and Modell 2004; Modell 1992). The resulting estimates contributed to several WHO reports (World Health Organization 2000; World Health Organization and March of Dimes 2006), provided the quantitative basis for the influential March of Dimes Global Report on Birth Defects (Christianson et al. 2006) and contributed baseline estimates for the "Born Healthy"(http:// www.bornhealthy.org) Needs Assessment Toolkit (Nacul et al. 2014). WHO endorsement of the March of Dimes estimates led in turn to inclusion of congenital disorders in the Global Burden of Disease study (Lopez et al. 2006), and a Resolution on Birth Defects by the World Health Assembly (World Health Organization and 2010).

The Executive Board's first recommendation to the World Health Assembly was "to promote the collection of data on the global burden of mortality and morbidity due to birth defects", and the resolution included the recommendation to "resolve currently divergent opinions on the health burden of both environmental and constitutional birth defects". We therefore formed an informal international expert group to 
Table 1 Classical studies of the birth prevalence of congenital disorders

\begin{tabular}{llll}
\hline Source & $\begin{array}{l}\text { Chromosomal } \\
\text { disorders }\end{array}$ & $\begin{array}{l}\text { Congenital } \\
\text { malformations }\end{array}$ & $\begin{array}{l}\text { Rare single-gene } \\
\text { disorders }\end{array}$ \\
\hline Neel (1958) & & + & + \\
Stevenson (1959) & + & + & + \\
Stevenson et al. (1966) & + & + & + \\
Trimble and Doughty (1974) & + & + & + \\
$\begin{array}{l}\text { Myrianthopoulos and Chung } \\
\quad(1974)\end{array}$ & & + & + \\
Ash et al. (1977) & + & + & + \\
Hook and Hamerton (1977) & + & & + \\
Carter (1977) & & + & \\
Czeizel and Sankaranarayanan & + & & \\
$\quad(1984)$ & & &
\end{tabular}

All studies include only disorders that cause death or disability in the absence of intervention develop and review methods for estimating birth prevalence and outcomes of congenital disorders, compliant with the recommendations of the Guidelines for Accurate and Transparent Health Estimates Reporting (GATHER) Working Group (Stevens et al. 2016).

\section{The Modell Global Database of Congenital Disorders}

Congenital disorders can be divided into five groups: environmental disorders (due to maternal exposure to, e.g. infection or other hazards), chromosomal disorders, congenital malformations, single-gene disorders and disorders due to common genetic risk factors (Fig. 1). In the absence of

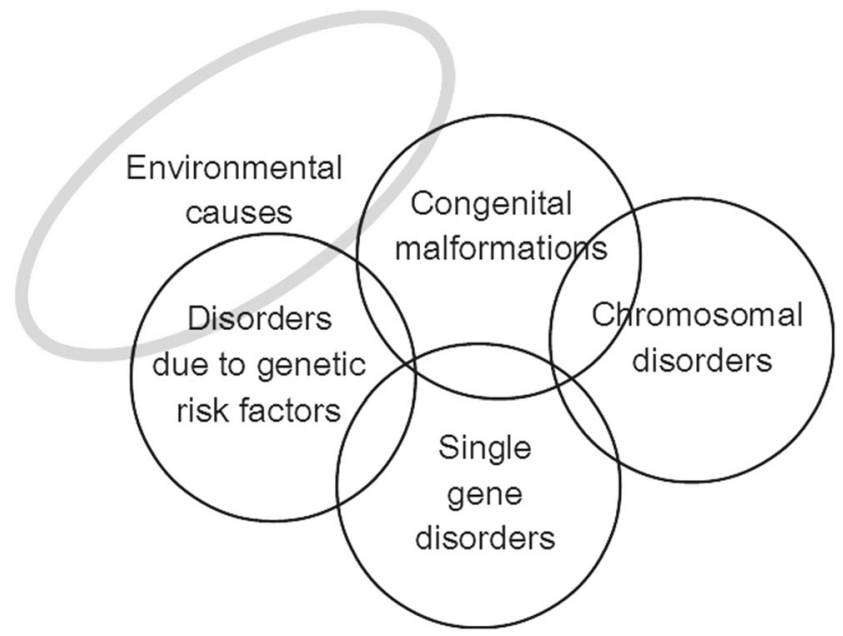

Fig. 1 The main groups of congenital disorders. The image is notional: there is no relation between frequency and the size of the circles, or actual extent of overlap between categories. MGDb currently includes only the groups whose birth prevalence is relatively constant or can be calculated, namely chromosomal disorders, early-onset congenital malformations, single-gene disorders and two examples of common early-onset disorders due to genetic risk factors-rhesus haemolytic disease and neonatal jaundice due to glucose-6-phosphate dehydrogenase deficiency. intervention, the birth prevalence of four of these groups is largely determined by endogenous causes, so is relatively constant for any given population, and may be called their baseline birth prevalence. Sufficient data is available to obtain country-specific estimates of baseline birth prevalence for these four disorder groups (Modell et al. 2016; Moorthie et al. 2017a).

The availability of a baseline birth prevalence is an unusual, possibly unique, characteristic. It offers exceptional advantages from an epidemiological point of view because once it is known, it can be related to available demographic and survival data and the observed effects of interventions, to reach country-specific estimates of the distribution of actual outcomes, including termination of pregnancy, fetal death, under-five death, disability and cure. Furthermore, the sum of outcomes must fill the original "envelope" of baseline birth prevalence. That is, these disorder groups can be handled as closed systems. In view of this important characteristic, these four groups are here collectively called constitutional congenital disorders.

The MGDb exploits this exceptional characteristic to generate evidence-based country, regional and global estimates of the birth prevalence and outcomes of constitutional congenital disorders that can be used as a starting point for service planning.

Currently, MGDb does not include congenital disorders caused by environmental risk factors such as maternal infection, malnutrition or exposure to teratogens. This is not to detract from the relevance of "environmental" congenital disorders. They have high priority because they can be largely prevented by basic public health interventions including sanitation, immunisation, nutritional supplementation, restriction of exposure to teratogens and diagnosis and treatment for the mother before or during pregnancy, and so occupy an important position in WHO recommendations for pregnancy care (World Health Organisation 2013). They are not currently 
included in MGDb because their baseline birth prevalence is determined by exposure to risk and so varies with place, time and deployment of interventions. Ongoing surveillance or periodic surveys are required to follow their epidemiology but resources for surveillance are most limited in the countries where they are most prevalent. Therefore, insufficient country- and time-specific observational data are available to permit the form of modelling used in MGDb. Should sufficient data become available, they might be included in the future.

In building MGDb, we developed a subset of epidemiological methods specific to congenital disorders that are simple enough for use by non-specialist health professionals. The articles in this special issue of the Journal of Community Genetics provide an introduction to these methods. Of equal importance, we encountered many examples of ill-defined or ambiguous terminology, so that it was necessary to establish precise definitions of all terms used. Selected country-specific outputs, a full description of the methods and the terminology used are available online at http://discovery.ucl.ac.uk/ 1532179/ (Modell et al. 2016).

\section{Other sources of data on epidemiology of congenital disorders}

The Global Burden of Disease (GBD) study has also published country-specific estimates of mortality and disability due to congenital anomalies, haemoglobin disorders and G6PD deficiency. The methods used by GBD differ from those used in MGDb and this leads to wide differences between the estimates. For example, the omission by GBD of stillbirths and terminations of pregnancy for fetal impairment leads to serious underestimation of the burden of congenital anomalies in high-income settings (Boyle et al. 2017), whilst the lack of accurate cause of death data in low- and middleincome countries leads to serious underestimation of early mortality due to congenital anomalies by the GBD (Boyle et al. 2017; Moorthie et al. 2017a). In addition, the fact that estimates for early-onset single-gene disorders, rhesus haemolytic disease and kernicterus due to G6PD deficiency are included in MGDb but not in the GBD widens the ostensible difference between the estimates.

Conclusions Congenital disorders continue to be important contributors to mortality and disability. The need for epidemiological data in this field has been recognised for decades. Policy and service development are reliant on such data to assess the burden of disease and the impact of interventions. Efforts such as the establishment of registries and research studies help to generate evidence to support policy, but there is still a lack data from low- and middle-income countries.
Simple methods that enable policymakers to make up for this deficiency are needed as a starting point.

Funding This work was supported by grants from the Wellcome Trust and WHO Regional Office for the Eastern Mediterranean.

\section{Compliance with ethical standards}

This article does not contain any studies with human or animal subjects performed by any of the authors.

Conflict of interest The authors declare that they have no conflict of interest.

Open Access This article is distributed under the terms of the Creative Commons Attribution 4.0 International License (http:// creativecommons.org/licenses/by/4.0/), which permits unrestricted use, distribution, and reproduction in any medium, provided you give appropriate credit to the original author(s) and the source, provide a link to the Creative Commons license, and indicate if changes were made.

\section{References}

Alwan AD, Modell B, Bittles A, Czeizel A, Hamamy H (1997) Community control of genetic and congenital disorders. WHO EMRO technical publication, vol no 24. WHO regional office for the eastern Mediterranean, Alexandria

Ash P, Vennart J, Carter CO (1977) The incidence of hereditary disease in man. Lancet 1:849-851

Baird PA (1987) Measuring birth defects and handicapping disorders in the population: the British Columbia Health Surveillance Registry. CMAJ 136:109-111

Baird PA, Anderson TW, Newcombe HB, Lowry RB (1988) Genetic disorders in children and young adults: a population study. Am J Hum Genet 42:677-693

Bittles AH, Black ML, (2015) Global patterns and tables of consanguinity. http://consang.net/. Accessed 4 Sept 2018

Blencowe $\mathrm{H}$ et al. (2018) Rare single gene disorders: estimating baseline prevalence and outcomes worldwide. J Community Genet https:// doi.org/10.1007/s12687-018-0376-2

Boyle B et al. (2017) Estimating Global Burden of Disease due to congenital anomaly: an analysis of European data arch dis child fetal neonatal Ed https://doi.org/10.1136/archdischild-2016-311845

Carter CO (1977) Monogenic disorders. J Med Genet 14:316-320

Christianson A, Modell B (2004) Medical genetics in developing countries. Annu Rev Genomics Hum Genet 5:219-265. https://doi.org/ 10.1146/annurev.genom.5.061903.175935

Christianson A, Howson CP, Modell B (2006) March of Dimes Global Report on Birth Defects: the hidden toll of dying and disabled children. March of Dimes Birth Defects Foundation, White Plains, New York

Czeizel A, Sankaranarayanan K (1984) The load of genetic and partially genetic disorders in man. I. Congenital anomalies: estimates of detriment in terms of years of life lost and years of impaired life. Mutat Res 128:73-103

Czeizel AE (1997) First 25 years of the Hungarian congenital abnormality registry. Teratology 55:299-305. https://doi.org/10.1002/(SICI) 1096-9926(199705)55:5<299::AID-TERA1>3.0.CO;2-V

Czeizel AE (2012) Experience of the Hungarian preconception service between 1984 and 2010. Eur J Obstet Gynecol Reprod Biol 161:18 25. https://doi.org/10.1016/j.ejogrb.2011.12.019 
Czeizel AE, Dobo M, Dudas I, Gasztonyi Z, Lantos I (1998) The Hungarian periconceptional service as a model for community genetics. Community Genet 1:252-259

Czeizel AE, Dudas I (1992) Prevention of the first occurrence of neuraltube defects by periconceptional vitamin supplementation. $\mathrm{N}$ Engl $\mathrm{J}$ Med 327:1832-1835. https://doi.org/10.1056/ NEJM199212243272602

Czeizel AE, Intody Z, Modell B (1993) What proportion of congenital abnormalities can be prevented? BMJ 306:499-503

Czeizel AE, Toth M, Rockenbauer M (1996) Population-based case control study of folic acid supplementation during pregnancy. Teratology 53:345-351. https://doi.org/10.1002/(SICI)10969926(199606)53:6<345::AID-TERA5>3.0.CO;2-Z

Hook EB, Hamerton J (1977) The frequency of chromosome abnormalities detected in consecutive newborn studies - differences between studies - results by sex and by severity of phenotypic involvement. In: Hook EB, Porter IH (eds) Population cytogenetics: studies in humans. Academic Press, New York

Livingstone FB (1985) Frequencies of hemoglobin variants: thalassemia, the glucose-6-phosphate dehydrogenase deficiency, G6PD variants, and ovalocytosis in human populations. Oxford University Press, New York

Lopez AD, Mathers CD, Ezzati M, Jamison DT, Murray CJL (2006) Measuring the global burden of disease and risk factors, 19902001. In: Lopez AD, Mathers CD, Ezzati M, Jamison DT, Murray CJL (eds) global burden of disease and risk factors. Washington (DC),

Modell B (1992) The need for a science of community genetics birth defects. Orig Artic Ser 28:131-141

Modell B, Darlison M (2008) Global epidemiology of haemoglobin disorders and derived service indicators Bull World Health Organ 86: 480-487

Modell B, Darlison MW, Moorthie S, Blencowe H, Petrou M, Lawn J (2016) Epidemiological methods in community genetics and the Modell Global Database of Congenital Disorders (MGDb) downloaded from UCL discovery. http://discoveryuclacuk/ 1532179/. Accessed 4 Sept 2018

Moorthie S, Blencowe H, Darlison MW, Lawn JE, Mastroiacovo P, Morris JK, Modell B, Congenital Disorders Expert Group (2017a) An overview of concepts and approaches used in estimating the burden of congenital disorders globally. J Community Genet. https://doi.org/10.1007/s12687-017-0335-3

Moorthie S, Blencowe H, Darlison MW, Gibbons S, Lawn JE, Mastroiacovo P, Morris JK, Modell B, Congenital Disorders Expert Group (2017b) Chromosomal disorders: estimating baseline birth prevalence and pregnancy outcomes worldwide. J Community Genet. https://doi.org/10.1007/s12687-017-0336-2

Mourant AE, Domaniewska-Sobczak K, Kopec AC, Tills D, Tills RE (1976) The distribution of the human blood groups and other polymorphisms. 2nd ed.; [and] Suppl.1. Edn. OUP, Oxford

Myrianthopoulos NC, Chung CS (1974) Congenital malformations in singletons: epidemiologic survey. Report from the Collaborative Perinatal project. Birth Defects Orig Artic Ser 10(11):1-58

Nacul LC, Stewart A, Alberg C, Chowdhury S, Darlison MW, Grollman C, Hall A, Modell B, Moorthie S, Sagoo GS, Burton H (2014) A Toolkit to assess health needs for congenital disorders in low- and middle-income countries: an instrument for public health action. J Public Health (Oxf) 36:243-250. https://doi.org/10.1093/pubmed/ fdt048
Neel JV (1958) A study of major congenital defects in Japanese infants. Am J Hum Genet 10:398-445

Schull WJ (1958) Empirical risks in consanguineous marriages: sex ratio, malformation, and viability. Am J Hum Genet 10:294-343

Schull WJ (2003) The children of atomic bomb survivors: a synopsis. J Radiol Prot 23:369-384

Schull WJ, Otake M, Neel JV (1981) Genetic effects of the atomic bombs: a reappraisal. Science 213:1220-1227

Stevens GA, Alkema L, Black RE, Boerma JT, Collins GS, Ezzati M, Grove JT, Hogan DR, Hogan MC, Horton R, Lawn JE, Marušić A, Mathers CD, Murray CJL, Rudan I, Salomon JA, Simpson PJ, Vos T, Welch V, The GATHER Working Group (2016) Guidelines for accurate and transparent health estimates reporting: the GATHER statement. PLoS Med 13:e1002056. https://doi.org/10.1371/journal. pmed. 1002056

Stevenson AC (1959) The load of hereditary defects in human populations radiation research supplement 1:306-325

Stevenson AC, Johnston HA, Stewart MI, Golding DR (1966) Congenital malformations. A report of a study of series of consecutive births in 24 centres Bull World Health Organ 34 Suppl:9-127

Trimble BK, Doughty JH (1974) The amount of hereditary disease in human populations. Ann Hum Genet 38:199-223

United Nations Scientific Committee on the Effects of Atomic Radiation (1977) Sources and biological effects of ionising radiation 1977 report to the General Assembly, with Annexes United Nations Publications Sales number E.77.IX.I. New York

United Nations Scientific Committee on the Effects of Atomic Radiation (1982) Sources and biological effects. 1982 report to the General Assembly, with Annexes. United Nations Publications Sales number E.82.IX.06300P. New York

United Nations Scientific Committee on the Effects of Atomic Radiation (1986) Genetic and somatic effect of ionising radiation United Nations, New York

World Health Organization (1992) International Statistical Classification of Diseases and Related Health Problems. 10th revision. World Health Organization, Geneva

World Health Organization (1966) Haemoglobinopathies and allied disorders- report of a WHO Scientific Group vol no 338. World Health Organization Technical Report Series Geneva

World Health Organization (1972) Treatment of haemoglobinopathies and allied disorders. Report of a WHO Scientific Group. World Health Organization Technical Report Series 1972, No 509 Geneva

World Health Organization (1985) Community approaches to the control of hereditary diseases. Report of a WHO Advisory Group on Hereditary Diseases. Geneva 3-5 October 1985. Unpublished WHO document HMG/AG/85.10

World Health Organization (2000) Primary health care approaches for the control of congenital disorders and disability. Report of a WHO meeting Cairo, 6-8 December 1999. WHO/HGN/WG/00.1

World Health Organization (2010) Sixty-third world health assembly: Geneva, 17-21 May 2010,

World Health Organization (2013) Policy brief: preconception care: maximising the benefits for maternal and child health http://www. who.int/maternal_child_adolescent/documents/preconception care policy brief.pdf

World Health Organization, March of Dimes (2006) Management of birth defects and haemoglobin disorders: report of a joint WHO-March of Dimes meeting, Geneva, Switzerland, 17-19 May 2006. World Health Organization, Geneva 